\title{
Y a-t-il un intérêt agronomique à associer une culture commerciale et une plante de couverture ?*
}

\section{Cas d'une association blé ( Triticum aestivum L.) fétuque rouge (Festuca rubra L.)}

Mouna Ghiloufi ${ }^{1}$

Didier Picard ${ }^{1}$

Patrick Saulas ${ }^{1}$

Stéphane de Tourdonnet ${ }^{2}$

1 Inra

UMR 211 Agronomie

BP 01

78850 Thiverval-Grignon

France

<ghiloufi@grignon.inra.fr>

<picard@grignon.inra.fr>

<Patrick.Saulas@grignon.inra.fr>

2 Montpellier SupAgro

Institut des régions chaudes

INRA - UMR Innovation

1101 Avenue Agropolis

BP 5098

34093 Montpellier cedex 05

France

<Stephane.De-Tourdonnet@supagro.inra.fr>

\begin{abstract}
Résumé
Les plantes de couverture, de plus en plus utilisées en zone tropicale en raison de leur intérêt pour la durabilité des systèmes de culture, le sont très peu en zone tempérée. C'est pourtant un moyen efficace de développer les services écosystémiques à cette échelle. L'objet de ce travail est triple : i) analyser la possibilité de les implanter en même temps qu'une culture commerciale sans entraîner de trop forte baisse de rendement; ii) mesurer le supplément de matière organique susceptible de retourner au sol par l'allongement de la période d'utilisation du rayonnement photosynthétiquement actif ; iii) mesurer leur effet sur les risques de pollution des eaux par l'azote minéral. Un essai a été mis en place à Grignon en 1999-2001 (E1) et 2000-2002 (E2) pour étudier l'association d'une fétuque rouge (Festuca rubra L.) et d'un blé (Triticum aestivum L.), avec plusieurs modalités de compétition, obtenues en associant deux variétés de blé, à deux densités de semis, et deux de fétuque. Les blés ont été conduits avec un objectif de rendement en grains de $9 \mathrm{t} / \mathrm{ha}$. Ces rendements (moyenne de E1 et E2) ont été plus affectés par le choix de la variété de blé (Isengrain: 8,8 t/ha, Scipion: 7,2 t/ha) que par la présence de la fétuque (blé seul : 8,6 t/ha ; blé associé : 7,8 t/ha). La fétuque a un effet dépressif sur l'élaboration du nombre de grains mais cet effet a été partiellement compensé par le poids d'un grain. La variété de fétuque n'a pas eu d'effet, ni la densité de semis du blé. Dans la période entre la récolte du blé et le semis de la culture suivante, les fétuques antérieurement associées ont produit 3,3 t/ha de biomasse en E1 et 2,7 t/ha en E2. Elles ont fait baisser la quantité d'azote minéral du sol dans la couche 0-0,9 m sous le seuil de $2 \mathrm{~g} / \mathrm{m}^{2}$.
\end{abstract}

Mots clés : azote ; composante du rendement ; rayonnement ; sol ; système de culture.

Thèmes : productions végétales ; systèmes agraires.

\section{Abstract \\ Is there any agronomical interest in undersowing a cash crop with a cover crop? The case of a winter wheat (Triticum aestivum L.) undersown with a red fescue (Festuca rubra L.)}

Cover crops, which have proven to be efficient in increasing the sustainability of tropical cropping systems, are much less used in temperate ones. The aim of this work is triple: i) to study the way to undersow a cover crop simultaneously with a cash crop in temperate areas without impacting too strongly the yield of the cash crop ; ii) to measure the overproduction of organic matter to be buried into the soil due to the lengthening of the period of the PAR use in such systems; iii) to measure their impact on the risk of pollution of the ground water by nitrogen. Two two-year cycles of experimentation were carried out at Grignon in 1999-2001 (E1) and 2000-2002 (E2) to analyze the effect of red fescue (Festuca rubra L.), a turf grass selected as cover crop, on the wheat (Triticum aestivum L.) yield and its components and to observe its role during the following inter-crop. Several conditions of competition between the two species were analyzed: undersowing two wheat varieties at two sowing rates, two red fescue varieties, sole crops being compared with undersown ones. The wheat yield target

\footnotetext{
* Pour citer cet article: Ghiloufi M, Picard D, Saulas P, de Tourdonnet S. Y a-t-il un intérêt agronomique à associer une culture commerciale et une plante de couverture? Cas d'une association blé (Triticum aestivum L.) fétuque rouge (Festuca rubra L.). Cah Agric 2010 ; 19 : 42031. doi : 10.1684/agr.2010.0438
} 
was $9 \mathrm{t} / \mathrm{ha}$. Wheat yields depended more on the wheat variety (Isengrain: $8.8 \mathrm{t} / \mathrm{ha}$, Scipion: $7.0 \mathrm{t} / \mathrm{ha}$ ) than on the red fescue undersowing (sole wheat: $8.6 \mathrm{t} / \mathrm{ha}$; undersown wheat: $7.8 \mathrm{t} / \mathrm{ha}$ ). Undersowing had statistically significant effects for the lower wheat sowing rate. Yield component analysis showed that the undersowing had a depressive effect on the number of kernels per $\mathrm{m}^{2}$. This effect was partially compensated for by a higher kernel weight in undersown wheat than in sole wheat. The red fescue variety and wheat sowing rate had no effect. During the time period between the wheat harvest and the sowing of the next cash crop, previously undersown fescue produced $3.3 \mathrm{t} / \mathrm{ha}$ in E1 and $2.7 \mathrm{t} / \mathrm{ha}$ in E2. The amount of soil mineral nitrogen in the 0-0.9 $\mathrm{m}$ layer decreased under the $2 \mathrm{~g} / \mathrm{m}^{2}$ threshold.

Key words: cropping systems; nitrogen; radiation; soil; yield components.

Subjects: farming systems; vegetal productions.

es plantes de couverture sont de plus en plus utilisées dans les successions culturales pour leur rôle de facilitation (Vandermeer, 1989), les objectifs recherchés étant fonction des types de systèmes de culture et des conditions environnementales (Malézieux et al., 2009). Dans le cas des systèmes de culture conventionnels, cet objectif est l'accroissement de la productivité (Blaser et al., 2006), la lutte contre l'érosion (Blackshaw et al., 2001) et la lixiviation des nitrates (Blackshaw et al., 2001; Känkänen et Eriksson, 2007 ; Whitmore et Schröder, 2007). Dans les systèmes en non-labour et semis direct, les plantes de couverture sont introduites pour maintenir la structure du sol dans un état favorable, accrô̂tre sa teneur en matière organique, et réduire le développement des adventices (Holland, 2004; Carof et al., 2007a ; 2007b). Les espèces à choisir et les conditions d'implantation ont également été très étudiées dans le cadre de l'agriculture biologique. La plante de couverture est alors le plus souvent une légumineuse, pour l'apport d'azote qu'elle entraîne (Thorsted et al., 2006).

La compétition entre une culture commerciale, dont le blé (Triticum aestivum L.), et les adventices, notamment les graminées, a été particulièrement étudiée afin de réduire leurs effets (Lemerle et al., 2001 ; Mason et Spaner, 2006). Mais les associations entre une culture commerciale et une plante de couverture posent un problème de nature différente : il faut à la fois ne pas entraîner de baisse de rendement trop forte de la culture commerciale et avoir une croissance suffisante de la plante de couverture pour qu'elle puisse pleinement jouer son rôle : accroître la part de rayonnement photosynthétiquement actif (PAR) capté à l'échelle du système de culture et absorber l'azote minéral du sol disponible après le blé. Les travaux de Carof et al. (2007a) ont montré des baisses de rendement élevées du blé dans le cas de semis direct dans deux peuplements de graminées et quatre peuplements de légumineuses. En revanche, dans un article antérieur (Picard et al., 2010), nous avons montré que le semis simultané de blé et de fétuque rouge (Festuca rubra L.) se traduisait par une diminution de rendement plus réduite, voire nulle. Le choix de la fétuque rouge a été fait d'une part parce qu'il s'agit d'une espèce gazonnante, de faible développement et supportant l'ombrage, d'autre part parce qu'elle utilise les mêmes ressources que le blé, en particulier pour l'azote. Elle était donc susceptible de ne pas être trop compétitive tout en étant en mesure de s'installer. Une légumineuse fixant l'azote athmosphérique aurait pu l'être davantage.

L'objectif de cette étude est triple: i) déterminer les effets de la fétuque rouge sur les composantes du rendement du blé (Meynard et David, 1992) afin de voir quand s'établit la compétition et quelles en sont les conséquences sur le rendement du blé ; ii) évaluer le PAR intercepté par la fétuque après la récolte du blé et la production de biomasse qui en résulte ; iii) évaluer la dynamique de l'azote minéral du sol dans la même période.

\section{Matériel et méthode}

Pour répondre aux hypothèses, un essai a été mis en place durant deux campagnes culturales, 1999-2001 (E1) et 2000-2002 (E2), à Thiverval-Grignon ( $48^{\circ} 50^{\prime} \mathrm{N}$, $\left.1^{\circ} 56^{\prime} \mathrm{E}\right)$, au cour du Bassin parisien. Le sol est constitué d'un horizon limono- argileux reposant sur une couche calcaire (Orthic Luvisol, classification FAOUnesco). La texture des horizons de surface à pH basique est, en E1, de $281 \mathrm{~g} / \mathrm{kg}$ d'argile, $599 \mathrm{~g} / \mathrm{kg}$ de limon et $120 \mathrm{~g} / \mathrm{kg}$ de sable; en E2, de $261 \mathrm{~g} / \mathrm{kg}$ d'argile, $649 \mathrm{~g} / \mathrm{kg}$ de limon et $90 \mathrm{~g} / \mathrm{kg}$ de sable. La couche calcaire limite la profondeur du sol à 60-90 cm dans E1, à 90-120 cm en E2. La période des essais a bénéficié de pluies abondantes par rapport aux moyennes de la région à l'exception des mois de janvier 2000, mai, juin et décembre 2001, janvier 2002 (tableau 1). Les températures ont été fréquemment plus élevées que la moyenne.

Les traitements expérimentaux ont été choisis de façon à faire varier la pression de compétition en jouant sur l'architecture des variétés de blé et de fétuque et sur la densité de semis du blé. Les deux variétés de blé, Isengrain et Scipion, ont été choisies à partir de notes (de 0 à 20, selon la hauteur de la plante, sa résistance à la verse, son port au tallage et le port de sa dernière feuille) attribuées pour leur aptitude à servir de plantes abris pour la production de semences de graminées à gazon. Plus la note est faible (Isengrain, 10 ; Scipion, 18) plus la plante est " agressive " par rapport à la fétuque. Isengrain a un potentiel de tallage plus élevé; Scipion a un port plus dressé, laissant davantage de rayonnement filtrer dans le couvert. Les blés ont été semés à deux densités - d1, $150 \mathrm{pl} . / \mathrm{m}^{2}$, et $\mathrm{d} 2$, $350 \mathrm{pl} . / \mathrm{m}^{2}$ - qui représentent des extrêmes par rapport à la densité $\left(250 \mathrm{pl} . / \mathrm{m}^{2}\right)$ généralement observée dans la région. La fétuque Sunset (F. rubra rubra) est une variété octoploïde à port rampant et à rhizomes; elle forme un gazon lâche bien couvrant. Center (F. rubra commutata) est une variété hexaploïde 


\section{Tableau 1. Pluviosité ( $\mathrm{mm}$ ) mensuelle et température moyenne mensuelle $\left(^{\circ} \mathrm{C}\right)$ durant la période de l'essai. Écarts aux moyennes trentenaires (Versailles, 1968-1998).}

Table 1. Monthly precipitation $(\mathrm{mm})$ and mean monthly temperatures $\left({ }^{\circ} \mathrm{C}\right)$ during the experimental period. Differences compared to 30 year mean (Versailles, 1968-1998).

\begin{tabular}{|c|c|c|c|c|c|c|c|c|c|c|c|c|c|}
\hline & Mois & $\mathbf{J}$ & $\mathbf{F}$ & $\mathbf{M}$ & A & $\mathbf{M}$ & $\mathbf{J}$ & $\mathbf{J}$ & A & $\mathbf{S}$ & 0 & $\mathbf{N}$ & D \\
\hline Années & & \multicolumn{12}{|c|}{ Pluviosité (mm) } \\
\hline \multirow[t]{2}{*}{1999} & Moyenne & & & & & & & 25,0 & 99,5 & 113,5 & 47,8 & 42,4 & 150,2 \\
\hline & Écart & & & & & & & $-33,3$ & 52,3 & 57,5 & $-8,8$ & $-11,2$ & 94,7 \\
\hline \multirow[t]{2}{*}{2000} & Moyenne & 18,8 & 52,6 & 39,6 & 97,2 & 93,6 & 44,8 & 142,6 & 59,6 & 41,7 & 122,4 & 82,2 & 69,0 \\
\hline & Écart & $-37,7$ & 4,3 & $-10,9$ & 47,3 & 33,7 & $-8,1$ & 84,3 & 12,4 & $-14,3$ & 65,8 & 28,6 & 13,5 \\
\hline \multirow[t]{2}{*}{2001} & Moyenne & 54,2 & 39,6 & 128,2 & 64,4 & 19,4 & 20,6 & 140,0 & 58,6 & 80,6 & 55 & 48 & 36,4 \\
\hline & Écart & $-2,3$ & $-8,7$ & 77,7 & 14,5 & $-40,5$ & $-32,3$ & 81,7 & 11,4 & 24,6 & $-1,6$ & $-5,6$ & $-19,1$ \\
\hline \multirow[t]{3}{*}{2002} & Moyenne & 25,8 & 76,2 & 62,8 & & & & & & & & & \\
\hline & Écart & $-30,7$ & 27,9 & 12,3 & & & & & & & & & \\
\hline & & \multicolumn{12}{|c|}{ Température $\left({ }^{\circ} \mathrm{C}\right)$} \\
\hline \multirow[t]{2}{*}{1999} & Moyenne & & & & & & & 20,6 & 19,6 & 18,1 & 11,6 & 6,0 & 5,3 \\
\hline & Écart & & & & & & & 2,5 & 1,5 & 3,1 & 0,2 & $-0,8$ & 0,9 \\
\hline \multirow[t]{2}{*}{2000} & Moyenne & 4,0 & 6,8 & 7,9 & 10,2 & 15,1 & 17,2 & 17,0 & 19,4 & 16,4 & 11,9 & 8,3 & 7,1 \\
\hline & Écart & 0,2 & 2,6 & 1,0 & 1,1 & 2,2 & 1,3 & $-1,2$ & 1,4 & 1,4 & 0,5 & 1,5 & 2,8 \\
\hline \multirow[t]{2}{*}{2001} & Moyenne & 4,7 & 5,4 & 8,7 & 9,2 & 15,0 & 16,6 & 19,2 & 20,06 & 13,75 & 15,14 & 6,2 & 3,04 \\
\hline & Écart & 1,0 & 1,2 & 1,8 & 0,1 & 2,0 & 0,7 & 1,1 & 2,03 & $-1,25$ & 3,75 & $-0,62$ & $-1,3$ \\
\hline \multirow[t]{2}{*}{2002} & Moyenne & 5,56 & 7,59 & 8,71 & & & & & & & & & \\
\hline & Écart & 1,79 & 3,39 & 1,85 & & & & & & & & & \\
\hline
\end{tabular}

à un port dressé, formant un gazon très dense. En E1, le dispositif expérimental comportait 12 traitements (tableau 2). En E2, ce dispositif a dû être modifié pour accroître la nature et la fréquence des observations et la précision des mesures, afin de mieux détecter les faibles effets de la présence de la fétuque. Seule- ment quatre des traitements de E1 ont été conservés, ceux pour lesquels la compétition de la fétuque vis-à-vis du blé est apparue la plus forte.

Le dispositif expérimental était constitué d'un split-plot répété 4 fois en E1, 6 fois en E2, avec, en parcelle principale le traitement fétuque, en sous parcelle le

\section{Tableau 2. Traitements et symboles du dispositif expérimental.}

Table 2. Treatments and labels of the experimental design.

\begin{tabular}{|c|c|c|}
\hline Traitements & Essai & Symbole \\
\hline Isengrain, 150 plantes $/ \mathrm{m}^{2}$ seul & E1, E2 & 11 \\
\hline Scipion, 150 plantes $/ \mathrm{m}^{2}$ seul & E1, E2 & S1 \\
\hline Isengrain, 350 plantes $/ \mathrm{m}^{2}$ seul & E1 & 12 \\
\hline Scipion, 350 plantes $/ \mathrm{m}^{2}$ seul & E1 & S2 \\
\hline Isengrain, 150 plantes $/ \mathrm{m}^{2}$ associé avec Center & E1 & $11 \mathrm{c}$ \\
\hline Isengrain, 150 plantes $/ \mathrm{m}^{2}$ associé avec Sunset & E1, E2 & I1su \\
\hline Isengrain, 350 plantes $/ \mathrm{m}^{2}$ associé avec Center & E1 & $12 \mathrm{c}$ \\
\hline Isengrain, 350 plantes $/ \mathrm{m}^{2}$ associé avec Sunset & E1 & $12 \mathrm{su}$ \\
\hline Scipion, 150 plantes $/ \mathrm{m}^{2}$ associé avec Center & E1 & S1c \\
\hline Scipion, 150 plantes $/ \mathrm{m}^{2}$ associé avec Sunset & $\mathrm{E} 1, \mathrm{E} 2$ & S1su \\
\hline Scipion, 350 plantes $/ \mathrm{m}^{2}$ associé avec Center & E1 & $\mathrm{S} 2 \mathrm{c}$ \\
\hline Scipion, 350 plantes $/ \mathrm{m}^{2}$ associé avec Sunset & E1 & S2su \\
\hline Center, 2000 plantes $/ \mathrm{m}^{2}$ seul & E1 & c \\
\hline Sunset, 1600 plantes $/ \mathrm{m}^{2}$ seul & E1, E2 & su \\
\hline
\end{tabular}

traitement variété de blé et, en E1, en sous-sous-parcelle le traitement densité de semis du blé (tableau 3). En E2, n'ont été conservées que la fétuque Sunset et la densité d1.

Le blé et la fétuque ont été semés le même jour: le 14 octobre 1999 en E1 et le 10 novembre 2000 en E2, de fortes pluies en octobre 2000 l'ayant retardé. Le précédent cultural en E1 a été un escourgeon, ce qui s'est traduit par une attaque de piétin échaudage (Gaeumanomyces

\section{Tableau 3. Traitements et symboles de l'analyse statistique.}

Table 3. Treatments and labels of the statistical analysis.

\begin{tabular}{ll}
\hline Symbole & Traitement \\
\hline $\mathrm{E}$ & Année (E1, E2) \\
$\mathrm{B}$ & Bloc \\
$\mathrm{F}$ & Avec Center (c), \\
& avec Sunset (su) ou sans \\
& fétuque (0) \\
$\mathrm{Vb}$ & Variété de blé (l, S) \\
$\mathrm{Db}$ & Densité de blé $(\mathrm{d} 1$, \\
& 150 pl./m $\left.; \mathrm{d} 2,350 \mathrm{pl} . / \mathrm{m}^{2}\right)$
\end{tabular}


graminis var. tritici). Pour limiter les risques en E2, l'essai a été implanté après un colza. Les densités de semis ont été réalisées avec un écartement entre lignes de $14,5 \mathrm{~cm}$ en $\mathrm{E} 1$, et $17,5 \mathrm{~cm}$ en E2. Les fétuques ont été semées immédiatement après les blés, à la volée, à environ 2000 graines $/ \mathrm{m}^{2}$ pour Center et 1600 graines $/ \mathrm{m}^{2}$ pour Sunset. La fertilisation en azote, la même sur toutes les parcelles, a été calculée selon la méthode des bilans pour un objectif de rendement des blés seuls de $9 \mathrm{t} / \mathrm{ha}$. Des pesticides n'ont été utilisés que sur avertissement de risque, pour maintenir les cultures dans un bon état sanitaire. Ainsi, un herbicide en post-levée a permis d'éliminer l'essentiel des adventices au début du printemps.

Les principaux stades de développement des deux variétés de blé ont été notés : levée, stade "épi à $1 \mathrm{~cm}$ " (e1), épiaison et floraison (Gate, 1995). Le nombre de plantes par mètre carré a été contrôlé par des comptages répétés, tous les 15 jours à 3 semaines, jusqu'à la mi-montaison sur 2 placettes par parcelle, de taille correspondant à 2 lignes de semis et $50 \mathrm{~cm}$ de long. À la récolte, le rendement du blé et ses composantes, nombre de plantes par mètre carré (npm2), nombre d'épis par plante (nepl), nombre de grains par épis (nge) et par mètre carré (nem2), poids de 1000 grains (p1g), ont été mesurés, sur 3 placettes dans E1, 4 dans E2. En E1, des notations de l'attaque de piétin échaudage ont été réalisées au stade miremplissage du grain: 40 tiges ont été prélevées au hasard dans chaque parcelle, la présence de symptômes notée " 1 ", l'absence notée " 0 ". La note par parcelle (en \%) est la somme des notes par tige. En $\mathrm{E} 2$, aucune attaque susceptible d'avoir un effet sur les rendements n'a été constatée. Après la récolte des blés (en E1, le 18 juillet 2000 ; en E2, le 23 juillet 2001), les pailles ont été exportées et une coupe a été effectuée sur les parcelles en fétuque seule, à la même hauteur que celle de la coupe des blés. En E1, 5 nouvelles mesures de biomasse des fétuques ont été réalisées jusqu'au 15 février 2001, la première (le 5 septembre 2000) sur l'ensemble des traitements, les suivantes sur une partie d'entre eux seulement, permettant de suivre les fétuques seules et celles qui étaient antérieurement en association, sans distinction du type d'association. Les prélèvements à la récolte du blé et le 5 septembre 2000 ont en effet montré l'absence d'effet de ce facteur. En E2, 8 prélèvements ont été effectués après la récolte du blé, jusqu'au 25 mars 2002 et sur les 3 traitements. Dans cette seconde période des essais, les biomasses fluctuent: il y a alternance de périodes d'augmentation et de périodes de réduction. Les productions ont été estimées en sommant les augmentations. Les surfaces foliaires ont aussi été mesurées et les indices foliaires (LAI) calculés.

Les teneurs en azote du sol ont été mesurées durant la période après la récolte du blé. L'efficience d'interception $\varepsilon_{\mathrm{i}} \mathrm{du}$ rayonnement photosynthétiquement actif (PAR) des fétuques, seule et précédemment associées, a également été mesurée en E2. $\varepsilon_{\mathrm{i}}$ a été calculé par la formule du bilan radiatif simplifié (Varlet-Grancher et al., 1989) :

$$
\varepsilon_{\mathrm{i}}=\left(\mathrm{PAR}_{0}-\mathrm{PAR}_{\mathrm{t}}\right) / \mathrm{PAR}_{0}
$$

où $\mathrm{PAR}_{0}$ est le rayonnement incident et $\mathrm{PAR}_{\mathrm{t}}$ la fraction de ce rayonnement transmise au sol.

L'indice global d'efficience d'interception

$$
\mathrm{IG} \varepsilon_{\mathrm{i}}=(1 / \mathrm{N})_{\mathrm{j}} \int \varepsilon_{\mathrm{ij}} \mathrm{d}_{\mathrm{j}}, \quad 0<\mathrm{j}<\mathrm{N}+1
$$

où $\mathrm{N}$ est la durée de l'essai, en jours depuis le semis, et $\varepsilon_{\mathrm{ij}}$ l'efficience d'interception au jour $\mathrm{j}$ du cycle. À partir des résultats sur les indices foliaires LAI $\left(\mathrm{m}^{2} / \mathrm{m}^{2}\right)$ et les efficiences d'interception du PAR, les coefficients d'extinction du rayonnement $\mathrm{K}$ dans les couverts de fétuques ont été calculés par :

$$
\varepsilon_{\mathrm{i}}=\varepsilon_{\text {imax }}\left[1-\exp \left(-\mathrm{K}^{*} \mathrm{LAI}\right)\right]
$$
$\mathrm{IG} \varepsilon_{\mathrm{i}}$ a été calculé par :

avec $\varepsilon_{\text {imax }}=$ constante $=0,95 . \mathrm{K}$ est la pente des droites de régression de -Ln $\left(1-\varepsilon_{\mathrm{i}}\right)$ sur LAI. Les méthodes décrites par ailleurs (Picard et al., 2010) ont été utilisées.

Les analyses de variance ont été faites à l'aide du logiciel SAS ${ }^{\circledR} 1999$, selon les procédures pour les dispositifs en splitplot. Les comparaisons de moyennes entre traitements ont été faites par le test de Newman et Keuls. La note d'attaque de piétin échaudage a été introduite en covariable pour les analyses de variance portant sur le rendement et les composantes affectées.

\section{Résultats}

\section{Rendements en grains du blé}

La première année (E1), les rendements en grains n'ont atteint l'objectif de 9 t/ha que pour les cultures d'Isengrain seul, aux deux densités de semis, d1 et d2 (figure 1). L'attaque de piétin échaudage dont les notes ont été beaucoup plus élevées dans les blocs 1 et 3 que dans les blocs 2 et 4 (tableau 4) les ont perturbés. L'association avec la fétuque, Center ou Sunset, entraîne leur diminution, mais les écarts avec les blés seuls ne sont pas significatifs. Les seules différences significatives concernent les variétés de blé : ceux d'Isengrain sont supérieurs de $17 \%$ en moyenne à ceux de Scipion (tableau 5). Il n'y a pas de différence significative en fonction des densités de semis du blé. Il n'y a pas non

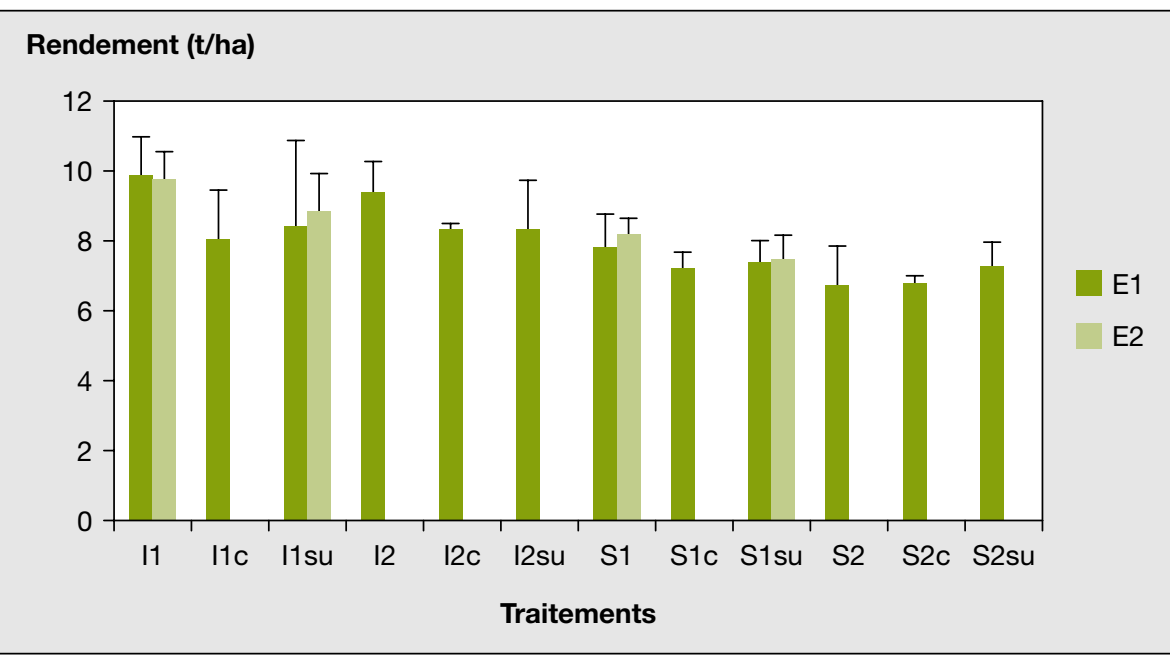

Figure 1. Rendements des blés.

Figure 1. Wheat yields.

Pour la nomenclature des traitements : voir le tableau 2. 
Tableau 4. E1, notes de piétin échaudage par bloc.

Table 4. E1, Take-all scores per block.

\begin{tabular}{lcccc}
\hline Bloc & $\mathbf{1}$ & $\mathbf{2}$ & $\mathbf{3}$ & $\mathbf{4}$ \\
\hline Note & 48 & 6 & 54 & 10 \\
\hline
\end{tabular}

plus de corrélation significative entre la biomasse de la fétuque à la moisson et les rendements en grains. L'analyse avec la note de piétin échaudage en covariable ne modifie que les résultats par bloc. La seconde année (E2), les rendements en grains des blés associés à Sunset sont significativement inférieurs à ceux des blés seuls. L'analyse sur les traitements communs à E1 et E2 le confirme : les différences de rendement entre présence et absence de fétuque Sunset associée au blé, de $9 \%$, sont significatives. Ce résultat était attendu, du fait du choix des traitements retenus. L'écart entre Isengrain et Scipion (16\%) est également significatif et supérieur à l'écart entre blé seul et blés associés.

\section{Analyse de la compétition blé-fétuque}

Le cycle des blés s'est déroulé sur 2687 degrés jours en E1 et 2591 degrés jours en E2. La durée semis-levée (tableau 6) a été beaucoup plus longue en E2 qu'en E1 et semblable pour les deux variétés. De ce fait, le stade "épi à $1 \mathrm{~cm}$ " (e1) a également été atteint plus tardivement. En revanche, la phase e1-épiaison a été plus courte en E2 qu'en E1. La durée de la phase épiaison-floraison est fonction aussi bien de l'année d'essai que de la variété de blé, mais, dans l'ensemble, la floraison a été plus tardive en E1 qu'en E2. Pour les composantes du rendement en grains (tableau 5), l'absence d'interaction significative entre l'effet fétuque $\mathrm{F}$, d'une part, et soit l'effet variété de blé Vb, soit l'effet densité de blé Db, d'autre part, montre que la compétition de la plante de couverture se manifeste de la même manière quel que soit le peuplement de blé auquel elle est associée. Il n'en est pas de même pour les biomasses, pour lesquelles certaines interactions sont significatives, sans que cela ait de conséquence visible sur les composantes du rendement du blé

Tout au long de leur cycle, les blés en association ont toujours dominé les fétuques en hauteur, malgré un étiolement marqué et une longueur de feuille significativement plus élevée pour les fétuques en association que pour les fétuques seules. Il n'y a pas d'effet de la variété de blé ni de sa densité de semis.

Trois étapes peuvent être distinguées dans l'élaboration du rendement en grains: l'établissement du nombre de plantes de blé par mètre carré (npm2) ; puis celle allant de l'élaboration du nombre d'épis par plante (nepl) et par mètre carré (nem2), au nombre de grains par épi (nge) et au nombre de grains par mètre carré (ngm2) ; enfin celle d'élaboration du poids d'un grain (p1g).

\section{Établissement du peuplement de blé}

Les npm2 sont établis à la sortie de l'hiver (figure 2A). En E1, le traitement présence) absence de fétuque associée au blé est sans effet sur le peuplement du blé

\section{Tableau 5. Analyses statistiques sur les composantes du rendement du blé.}

Table 5. Statistical analysis for wheat yield components.

\begin{tabular}{|c|c|c|c|c|c|c|c|c|c|c|}
\hline \multirow[b]{3}{*}{ Essais } & \multirow[b]{3}{*}{ Traitement (2) } & \multicolumn{4}{|c|}{ Composantes intermédiaires de ngm2 (1) } & \multirow[t]{2}{*}{ ngm2 } & \multicolumn{2}{|l|}{ p1g } & \multicolumn{2}{|c|}{ Rendement } \\
\hline & & npm2 & nepl & nem2 & nge & & & & & \\
\hline & & & & & & & & & & \\
\hline \multirow[t]{6}{*}{ E1/E2 (3) } & $\mathrm{E}$ & $* * * \mathrm{E} 1>\mathrm{E} 2$ & $* * \mathrm{E} 1<\mathrm{E} 2$ & ns & ${ }^{*} \mathrm{E} 1>\mathrm{E} 2$ & ns & $* * * \mathrm{E} 1<\mathrm{E} 2$ & & ns & \\
\hline & $\mathrm{F}$ & ns & ns & ns & $* 0>$ su & $* * 0>\mathrm{su}$ & ns & & ${ }^{*} 0>\mathrm{su}$ & \\
\hline & $\mathrm{Vb}$ & $* 1<S$ & ns & ns & $* * * 1>S$ & $* * \mid>S$ & $* 1<S$ & & $* * I>S$ & \\
\hline & $E \times F$ & ns & ns & ns & ns & ns & ${ }^{*} \mathrm{E} 1,0=\mathrm{s} \cup \mathrm{E} 2$ & , $0<\mathrm{su}$ & ns & \\
\hline & $\mathrm{E} \times \mathrm{Vb}$ & $\begin{array}{l}* * E 1, I<S \\
E 2, I \sim S\end{array}$ & ns & ns & ns & ns & ns & & ns & \\
\hline & Cov. m (4) & & & & & & Sans cov. & $\begin{array}{l}\text { Cov. m } \\
*\end{array}$ & Sans cov. & $\begin{array}{l}\text { Cov. m } \\
\text { ns }\end{array}$ \\
\hline \multirow[t]{6}{*}{ E1 } & B & ns & ns & $\mathrm{ns}$ & ns & ns & $*(4,2)(2,3,1)$ & ns & ns & ns \\
\hline & $\mathrm{F}$ & ns & ns & ns & ns & ns & ns & ns & ns & ns \\
\hline & $\mathrm{Vb}$ & $* * 1<S$ & $* * I>S$ & $* I>S$ & $* * * I>S$ & $* * * I>S$ & $* * 1<S$ & $* * 1<S$ & $* * 1>S$ & $* * 1>S$ \\
\hline & $\mathrm{Db}$ & $* * * \mathrm{~d} 1<<\mathrm{d} 2$ & $\stackrel{* *}{d 1}>d 2$ & $\begin{array}{l}* * * \\
\mathrm{~d} 1<\mathrm{d} 2\end{array}$ & $\begin{array}{l}* * * \\
\mathrm{~d} 1\end{array}>\mathrm{d} 2$ & ns & ns & ns & ns & ns \\
\hline & $\mathrm{F} \times \mathrm{Vb}$ & ns & ns & ns & ns & ns & $\begin{array}{l}{ }^{*} \mathrm{~S}, 0 \sim \mathrm{su} \sim \mathrm{C} \\
\mathrm{I}, \mathrm{O}>\mathrm{su} \sim \mathrm{C}\end{array}$ & ns & ns & ns \\
\hline & $\mathrm{Vb} \times \mathrm{Db}$ & $I^{* * *}=\mathrm{S} 1 \mathrm{I} 2<\mathrm{S} 2$ & ns & ns & ns & ns & ns & ns & ns & ns \\
\hline \multirow[t]{3}{*}{ E2 } & B & ns & ns & ns & ns & ns & ns & & ns & \\
\hline & $\mathrm{F}$ & ns & ${ }^{*} 0>$ su & ${ }^{*} 0>\mathrm{su}$ & ${ }^{*} 0 \sim \mathrm{su}$ & $* * 0>s u$ & $* * 0<\mathrm{su}$ & & ${ }^{*} 0>$ su & \\
\hline & $\mathrm{Vb}$ & ns & ns & ns & $* * * \mid>S$ & $* * \mid>S$ & ns & & $* * \mid>S$ & \\
\hline
\end{tabular}

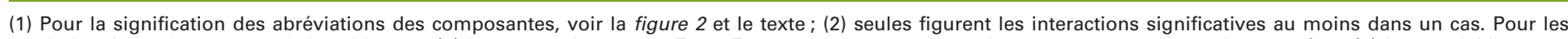

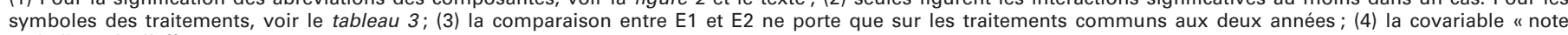
maladie " n'a d'effet que sur p1g. 
Tableau 6. Durée nécessaire à la réalisation des principaux stades de développement du blé, exprimée en sommes de températures (degrés jours, $d^{\circ} j$ ), en fonction des essais et des variétés.

Table 6. Time needed to reach main developmental stages of the wheat, in degree-days, according to experiments and varieties.

\begin{tabular}{lcccccc}
\hline Variété de blé & Essai & Semis-levée & Semis-épi à $\mathbf{1 ~ c m}$ & Semis-épiaison & Semis-floraison & Semis-récolte \\
\hline Échelle de Zadoks (1) & & 11 & 30 & 55 & 65 & \\
\hline Isengrain & 1 & 111 & 963 & 1627 & 1793 & 2687 \\
& 2 & 212 & 999 & 1500 & 1664 & 2591 \\
\hline Scipion & 1 & 111 & 963 & 1645 & 1765 & 2687 \\
& 2 & 212 & 999 & 1436 & 1644 & 2591 \\
\hline
\end{tabular}

(1) Zadoks et al. (1974).

(tableau 5). Si les objectifs initiaux de densité de semis ont été plus ou moins bien atteints selon les variétés de blé, c'est en raison de la surestimation du poids des semences d'Isengrain au semis. Pour les biomasses totales des blés (figure 3), les différences significatives sont essentiellement fonction de la variété et, dans la phase initiale de croissance jusqu'à e1, de la densité de semis. Ce dernier effet va s'estomper progressivement, le tallage permettant de compenser les écarts initiaux. L'implantation des fétuques par semis à la volée a donné lieu à un peuplement très irrégulier au sein d'une même parcelle et d'une parcelle à l'autre, en particulier en E2 (semé dans des conditions climatiques difficiles). L'association avec la fétuque Center a un effet légèrement dépressif aux premiers stades, effet qui disparaît au-delà du stade e1. Les biomasses produites par Isengrain sont peu différentes de celles de Scipion durant les phases initiales du cycle.

\section{Établissement du nombre de grains par mètre carré}

La présence de la fétuque réduit significativement les nombres de grains par épi (nge) et par mètre carré (nem2) en E2 et dans les traitements homologues de E1 (figures $2 A, 2 B, 2 C$ ) (tableau 5). En E1, les autres effets des traitements concernent les variétés de blé et les densités de semis. Toutes les composantes des ngm2 sont plus élevées pour Isengrain que pour Scipion. Les densités de semis affectent en sens inverse les nepl, plus élevés pour d1, et les nem2, plus élevés pour d2. En E2, la présence de la fétuque a des effets significatifs plus tôt dans le cycle du blé et réduit les premières composantes des ngm2, nepl et nem2.

En E1 comme en E2, les biomasses d'Isengrain, seul ou associé, augmentent plus rapidement que celles de Scipion. La présence de fétuque associée n'a pas d'effet. En E1, les premières mesures de biomasse des fétuques effectuées entre le stade e1 et l'épiaison du blé montrent que celles-ci sont plus élevées pour celles qui sont en association avec Scipion à la densité d2 (350 pl./. $\mathrm{m}^{2}$ ) que pour celles qui sont en association avec Isengrain à la densité d2 et que pour les fétuques seules. La croissance rapide en biomasse ne commence vraiment que vers $1200 \mathrm{~d}^{\circ} \mathrm{j}$ (figure 3) pour les fétuques seules et plus tard encore pour les fétuques associées, très en retard sur celle des blés. Les productions de biomasse sont plus élevées lors de E1 que lors de E2 et les écarts augmentent avec le temps, en particulier pour les fétuques seules. À partir de l'épiaison du blé, les biomasses des fétuques seules sont systématiquement plus élevées que celles des fétuques en association, les écarts continuant à croître jusqu'à la récolte des blés. En E1, celles produites par Sunset sont toujours supérieures à celles produites par Center.

\section{Poids d'un grain}

Les poids d'un grain (p1g) (figure 2c) diminuent lorsque les ngm2 augmentent. Mais pour l'ensemble des données, la corrélation est peu significative $\left(r=-0,52^{*}\right)$ : en effet, en E2, l'association avec la fétuque se traduit par une augmentation significative du p1g, alors qu'en E1 l'effet de l'association, qui va dans le même sens, est moins important et est partiellement masqué par l'attaque de piétin échaudage. Dans l'analyse des résultats de E1, cet effet de l'association n'est significatif (faiblement) qu'au niveau de l'interaction fétuque $\mathrm{x}$ variété de blé et disparaît avec l'introduction de la covariable ; c'est l'attaque de piétin échaudage, plus marquée sur les parcelles en blé associé du fait de la présence de la fétuque, qui est responsable des différences obser- vées (tableau 5). Les différences entre Isengrain et Scipion sont à l'inverse de celles concernant les ngm2: Scipion a un p1g plus élevé qu'Isengrain. En E2, la différence entre Isengrain et Scipion n'est pas significative. Pour les traitements communs à E1 et E2, le p1g a été plus élevé en E2, ce qui confirme les résultats par essai : l'effet de la fétuque associée n'est significatif qu'en E2 et l'écart entre Isengrain et Scipion n'y est pas significatif.

En E1, les biomasses d'Isengrain augmentent plus vite que celles de Scipion, jusqu'à la récolte. Il en est de même pour les biomasses épis dès leur différenciation. À la récolte, le piétin échaudage a eu un effet plus fort sur les biomasses des blés à forte densité de semis que sur celles des blés à faible densité. En E2, l'association avec la fétuque a un effet dépressif sur la production de biomasse totale à partir du stade floraison et jusqu'à la récolte. Les biomasses pour Isengrain sont supérieures aux biomasses pour Scipion à partir du même stade. Il n'y a pas d'interaction entre l'effet fétuque et l'effet variété de blé, ou l'effet densité de blé.

À la récolte des blés en E1, l'analyse des productions de biomasse des fétuques limitée aux peuplements associés montre un effet bloc marqué, la production étant meilleure dans les blocs affectés par le piétin échaudage: l'affaiblissement du blé en fin de cycle a favorisé la croissance de la fétuque.

\section{Effets de la présence d'une fétuque dans la phase postérieure à la récolte du blé}

\section{Production de matière sèche}

L'efficience d'interception $\varepsilon_{\mathrm{i}}$ du rayonnement photosynthétiquement actif (PAR) 


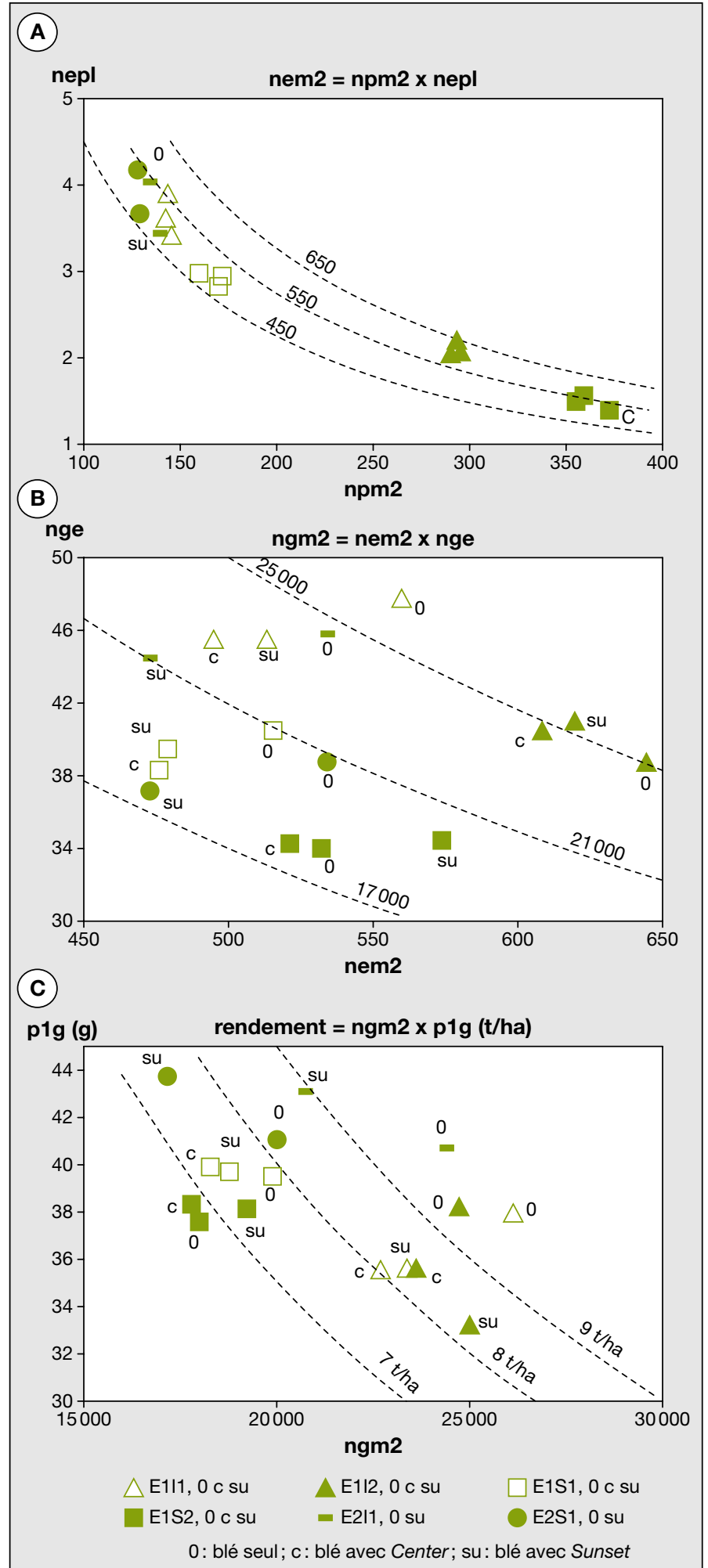

Figure 2. Composantes du rendement des blés en fonction des traitements.

Figure 2. Wheat yield components in relation to treatments.

Pour la nomenclature des traitements: voir le tableau 2. Npm2: nombre de plantes par $\mathrm{m}^{2}$; nepl: nombre d'épis par plante; nem $2:$ nombre d'épis par $\mathrm{m}^{2} ;$ nge : nombre de grains par épi ; ngm2: nombre de grains par $\mathrm{m}^{2} ; \mathrm{p} 1 \mathrm{~g}$ : poids de mille grains. en E2 pour Sunset seule (Fsu) baisse de $10 \%$ après la coupe et jusqu'à la fin du mois d'août (3030 d j environ) (figure 4), tout en restant très supérieure à celle des autres fétuques (FI1su et FS1su). La repousse a vraisemblablement été ralentie par la sécheresse à cette période (tableau 1). Puis $\varepsilon_{\mathrm{i}}$ réaugmente et reste proche de $95 \%$ jusqu'à la fin de l'essai. Les $\varepsilon_{\mathrm{i}}$ de FI1su et FS1su, qui étaient de l'ordre de $30 \%$ à la récolte des blés, d'abord stables, augmentent ensuite plus rapidement, mais ne rejoignent jamais celle de Fsu et plafonnent autour de $75 \%$, l'efficience de FI1su étant légèrement supérieure à celle de FS1su. Les coefficients d'extinction du rayonnement au sein du couvert sont respectivement de 0,83, 1,21 et 2,31 pour Fsu, FS1su et FI1su. La somme des valeurs de l'indice global d'interception du rayonnement IG $\varepsilon_{i}$ pendant la phase 1 du cycle du blé et pendant la phase $2-$ sol nu ou repousse de fétuque - (tableau 7) met clairement en évidence la bien meilleure valorisation du $\mathrm{PAR}_{0}$ dans le système de culture avec plante de couverture que dans celui où le sol reste nu dans l'interculture.

Après la récolte des blés, les biomasses des fétuques seules Fsu diminuent (figure 3), en raison de la coupe pratiquée. Puis la croissance reprend, de façon beaucoup plus rapide en E1 qu'en E2, mais avec des fluctuations marquées, alors que l'augmentation est régulière en E2. En fin d'essai, les biomasses des Fsu sont comparables. Les fétuques antérieurement en association FI1su et FS1su ont une croissance meilleure que les Fsu, mais insuffisante pour rattraper la biomasse totale accumulée par Fsu en fin d'essai. Les biomasses cumulées produites en fin d'essai par les associations sont plus élevées que celles produites par les blés et les fétuques seuls. Dans E1, la production totale de (BS1su+FS1su) représente $117 \%$ de la production de Scipion (BS1) et $166 \%$ de celle de Fsu. Dans E2, les chiffres sont de 108 et $242 \%$ respectivement. Les efficiences de transformation du PAR intercepté en biomasse (RUE) de FI1su et de FS1su ne sont pas différentes de celle de Fsu, soit RUE $=0,258$ pour la période du 23 juillet 2001 au 25 mars 2002.

La part de la matière sèche totale produite par les parties aériennes des peuplements associées depuis leur semis est constituée, d'une part des tiges et feuilles du blé (les enveloppes des grains de blé n'ont pas été prises en compte), en moyenne 8,3 t/ha, proportionnelle au rendement en grains 


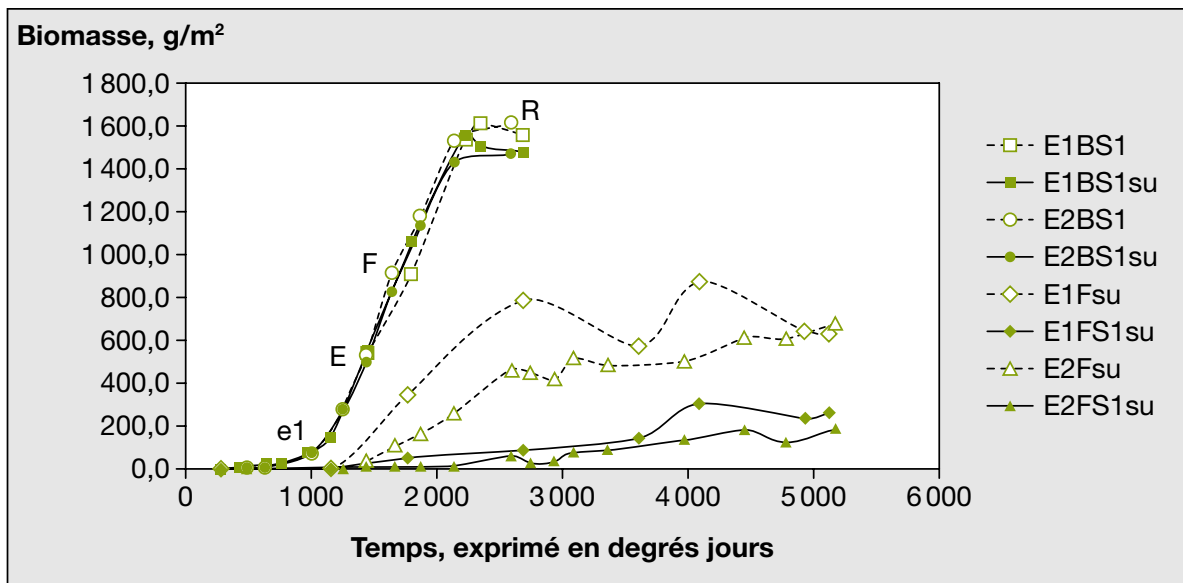

Figure 3. Total biomasses du blé Scipion et de la fétuque rouge Sunset en culture seule ou associée.

Figure 3. Total biomasses for Scipion wheat and Sunset red fescue undersown or alone.

E1: 1999-2000; E2: 2000-2001; B: blé; F: fétuque rouge; S1: variété Scipion, densité de semis 150 graines $/ \mathrm{m}^{2}$; S1su : association blé - fétuque ; su : variété Sunset. e1, E, F, R : stades du blé, respectivement 'épi à $1 \mathrm{~cm}$ ', épiaison, floraison et récolte.

Les courbes pour Isengrain sont très comparables à celles de Scipion, mais avec des biomasses plus élevées, particulièrement après le stade épiaison. Celles concernant Center en E1 sont très proches de celles de Sunset Elles n'ont pas été représentées pour ne pas surcharger la figure.

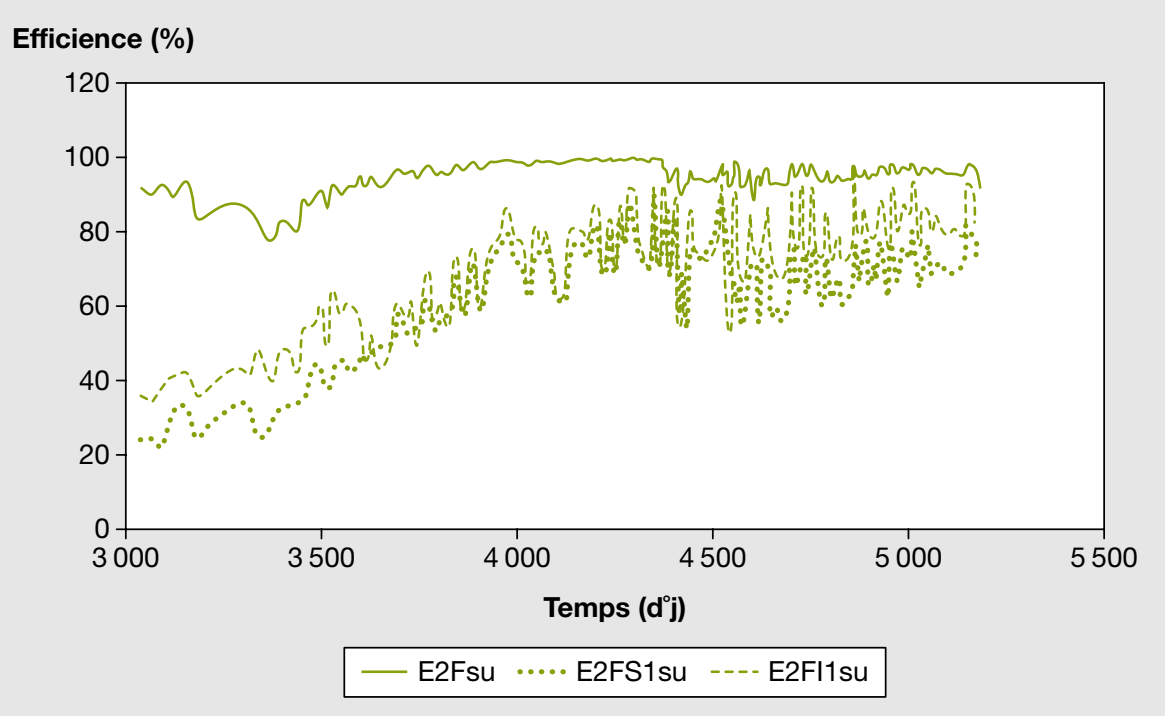

Figure 4. Évolution après la récolte du blé,en fonction du temps exprimé en degrés-jours $\left(d^{\circ} j\right)$, de l'efficience d'interception du rayonnement photosynthétiquement actif (PAR) des fétuques, précédemmenent seules (Fsu) ou associées à Isengrain (FI1su) ou Scipion (FS1su).

Figure 4. Time course after the wheat harvest, related to time in degree-days $\left(d^{\circ} j\right)$, of the interception efficiency of the photosyntheticaly active radiation (PAR) for the red fescues, previously alone (Fsu) or undersown with Isengrain (FI1su) or Scipion (FS1su).

(figure 5), et d'autre part de la biomasse des fétuques. Ce dernier apport est en moyenne de 3,3 t/ha de matière sèche en E1 et de 2,7 t/ha en E2. Il n'y a pas de corrélation entre la matière sèche totale produite par les blés et celle produite par la fétuque. alors qu'il réaugmente sous les parcelles S(B) (antérieurement en blé seul) (figure 6), en raison de l'absence de végétation et de la minéralisation de matière organique. Les fétuques seules ayant reçu la même fertilisation azotée que les blés seuls et les blés associés, les QN des parcelles $S(F)$ étaient très élevées en fin de $\Phi 1$, en particulier dans les horizons profonds $(30-60 \mathrm{~cm}$ et surtout $60-90 \mathrm{~cm})$. Elles diminuent fortement et deviennent comparables à celles des $\mathrm{S}(\mathrm{B}+\mathrm{F})$ lors des derniers prélèvements, en particulier dans l'horizon 0-10 cm. En E2, la même évolution qu'en E1 est observée mais avec des QN initialement beaucoup plus élevées sous $\mathrm{S}(\mathrm{F})$. Les écarts de QN entre parcelles $\mathrm{S}(\mathrm{B})$ et $\mathrm{S}(\mathrm{B}+\mathrm{F})$ sont significatifs dans la période comprise entre le $341^{\mathrm{e}}$ et le $391^{\mathrm{e}}$ jas (d'octobre à décembre). Puis les différences s'atténuent et ne sont plus significatives. Les valeurs sous $\mathrm{S}(\mathrm{F})$ sont très proches de celles sous $\mathrm{S}(\mathrm{B}+\mathrm{F})$ à partir du $341^{\mathrm{e}}$ jas. Les fétuques antérieurement associées aux blés ont donc pleinement joué leur rôle pour limiter la concentration en $\mathrm{N}$ minéral du sol et réduire les risques d'entraînement vers la profondeur des résidus de fertilisation du blé et de l'azote produit par la minéralisation de la matière organique du sol après la récolte.

\section{Discussion}

Une large gamme de conditions de compétition entre le blé et la fétuque a été explorée, incluant le climat, les variétés et les structures de peuplement. Les peuplements de fétuque ont été très hétérogènes, en raison des difficultés d'implantation généralement rencontrées avec les graminées à petites graines (Lemerle et al., 2004). Ces hétérogénéités se sont traduites par des écarts types entre résultats des répétitions élevés qui ont rendu les effets des traitements peu voire non significatifs, en particulier en première année, justifiant la modification du protocole expérimental entre E1 et E2. L'analyse statistique des notes de maladie de piétin échaudage qui a perturbé la fin du premier essai montre que la présence de fétuque a facilité son développement. Durant le cycle du blé, l'absence d'interaction significative entre l'effet fétuque $\mathrm{F}$ d'une part et soit l'effet variété de blé Vb, soit l'effet densité de blé Db, montre que la diversité des peuplements mis en place 
Tableau 7. Valeurs de l'indice global d'efficience d'interception du rayonnement $I G \varepsilon_{i}$ pendant le cycle du blé (1) puis dans la période de repousse de fétuque (2) et dans l'ensemble des 2 périodes $(1+2)$ en E2.

Table 7. Values of the global interception efficiency index IGei during the wheat growth (1), then during the period of the fescue regrowth (2) and during the two periods $(1+2)$ in E2.

\begin{tabular}{lcccc}
\hline & I1 & s1 & s1su & su \\
\hline 1 & 0,41 & 0,40 & 0,43 & 0,22 \\
2 & 0,00 & 0,00 & 0,63 & 0,94 \\
$1+2$ & 0,19 & 0,19 & 0,52 & 0,58 \\
\hline
\end{tabular}

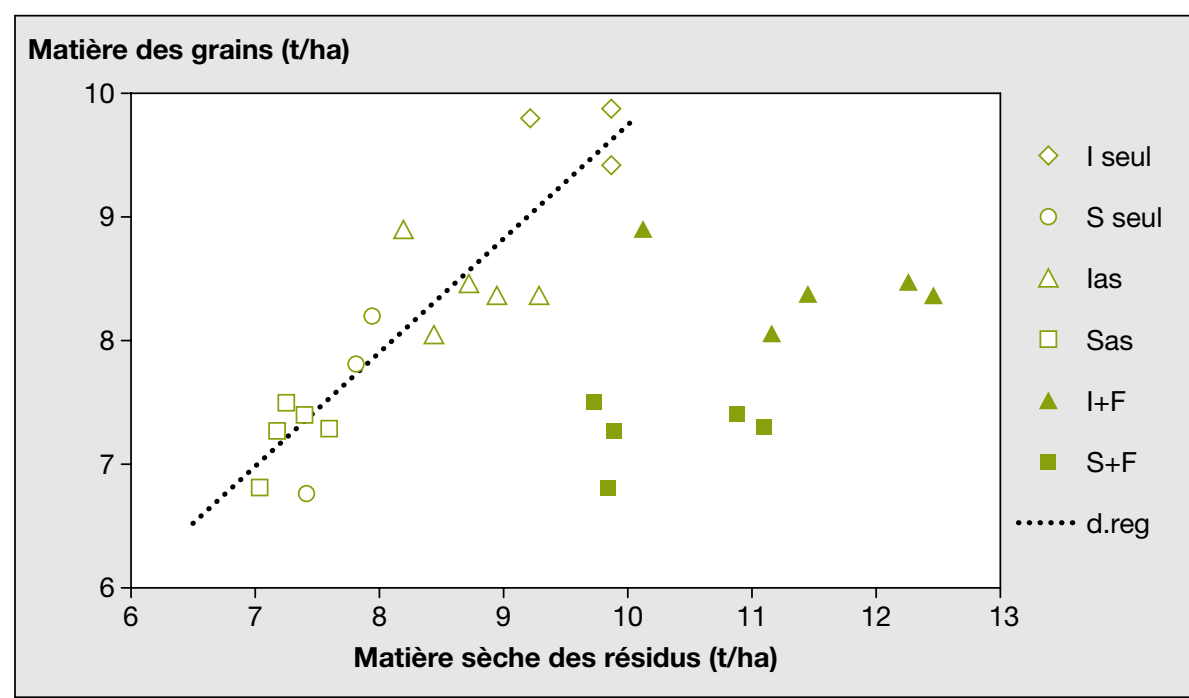

Figure 5. Comparaison des rendements en grains et des biomasses de résidus de culture en fin de cycle blé - repousse de fétuque.

Figure 5. Comparison between grain yields and biomasses of crop residues at the end of the time period wheat - fescue regrowth.

Les résidus susceptibles d'alimenter le « pool " des matières organiques du sol sont constitués par les tiges (T) et feuilles (F) des blés, ainsi que par la biomasse totale des fétuques.

I seul : Isengrain seul ; $\mathrm{S}$ seul : Scipion seul ; las : biomasse $(\mathrm{T}+\mathrm{F}) d^{\prime}$ Isengrain associé à fétuque ; Sas : biomasse $(T+F)$ de Scipion associé à fétuque ; $I+F$ : biomasse $\left[(T+F) d^{\prime} I s e n g r a i n\right.$ associé à fétuque + biomasse totale de la fétuque associée]; $\mathrm{S}+\mathrm{F}$ : biomasse $[(\mathrm{T}+\mathrm{F})$ de Scipion associé à fétuque + biomasse totale de la fétuque associée] ; d.reg : droite de régression entre matière sèche des grains et matière sèche des $(T+F)$ des blés.

ne modifie pas la nature des effets de la compétition entre les deux espèces sur les composantes du rendement en grains du blé. Seule varie l'amplitude de ces effets, selon les traitements. En début de cycle, la fétuque est sans effet sur l'établissement du peuplement de blé. Puis elle a un effet négatif limité sur les premières composantes du rendement en grains. Dans une troisième étape, le blé prend le dessus.

Les résultats s'expliquent partiellement par la compétition intraspécifique entre plantes et organes - talles, épis, grains (nombre, poids) - du blé au sein du peuplement (Fischer et Stockman, 1980 ; Masle-Meynard, 1982; Fischer, 1985), que viennent corriger des mécanismes de compensation ultérieurs (Sébillotte, 1980), et partiellement par la compétition interspécifique entre blé et fétuque.

Les mécanismes de compétition/compensation intraspécifique observés en E1 sont liés à la différence de densité de semis du blé : cette densité n'a pas d'effet sur le rendement, mais en a sur les composantes pendant tout le cycle du blé (MasleMeynard, 1982). La corrélation positive entre le nombre de grains par épi et le nombre d'épis par plante, rarement observée, est probablement due au fort écart entre $\mathrm{d} 1$ et $\mathrm{d} 2$ et aux différences variétales déjà mentionnées.

Les résultats de $\mathrm{E} 2$ et la comparaison entre E1 et E2 pour les traitements homologues montrent que les faibles densités de semis accroissent la compétition des fétuques sur la production de grains des blés, comme l'ont déjà observé les auteurs qui ont étudié celle qui se produit entre du blé et des graminées adventices (Lemerle et al., 2001a ; Derksen et al., 2002 ; Mason et Spaner, 2006).

Cette compétition a des effets sur les composantes du nombre de grains par mètre carré qui se mettent en place à partir du stade e1 (Acciaresi et al., 2001 ; Carof et al., 2007a; et Carof et al., 2007b), lorsque la biomasse du blé commence à croitre rapidement, alors que celle de la fétuque associée est encore très faible. L'effet négatif précoce exercé par la fétuque reste mal expliqué. Il est limité dans la mesure où il n'apparaît pas en E1 et, en particulier, ne restreint pas le tallage du blé semé à faible densité. Les mécanismes de cette compétition sont vraisemblablement à rechercher au niveau des systèmes racinaires. L'évolution ultérieure de la compétition interspécifique s'explique par le démarrage plus rapide de la croissance du blé au printemps qui lui confère un avantage définitif et par le moindre développement en profondeur de l'enracinement des fétuques (Picard et al., 2010). Pour l'ensemble des traitements en E1, les mécanismes de compensation ont fait qu'il n'y a pas de différence de rendement en grains entre blés seuls et blés associés à la récolte. La compensation au niveau du poids d'un grain contribue à expliquer les différences de rendement moindres entre Scipion seul et associé qu'entre Isengrain seul et associé, la part relative du poids d'un grain dans le rendement étant plus élevée pour Scipion. Cela montre bien la nécessité d'observer en détail l'évolution des composantes du rendement dans le temps pour comprendre le comportement du peuplement (Angonin et al., 1996) : selon Kropff et Van Laar (1993), identifier le moment où la compétition commence à s'exercer est crucial pour en comprendre les effets. Nous pouvons également émettre l'hypothèse qu'implanter une plante de couverture en même temps qu'une culture commerciale est moins risqué avec une espèce capable de compensation entre ses composantes du rendement qu'avec une 


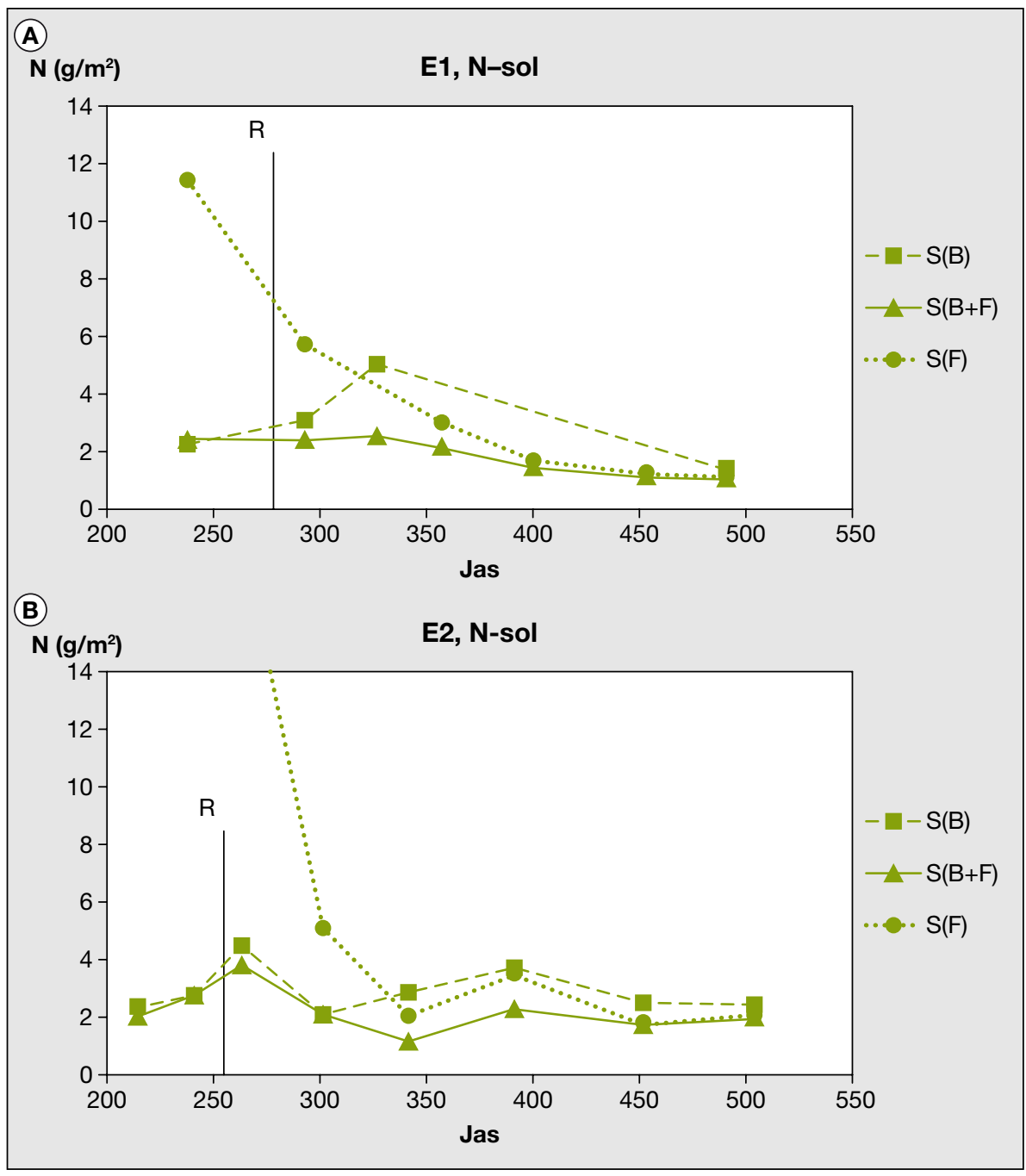

Figure 6. Évolution de la quantité totale d'azote minéral du sol sur l'ensemble du profil $(0-90 \mathrm{~cm})$ après la récolte du blé $(R)$.

Figure 6. Time course of the total amount of soil mineral nitrogen in the whole soil profile $(0-90 \mathrm{~cm})$ after the wheat harvest (R).

E1 : 2000-2001; E2 : 2001-2002 ; Jas : jours après semis du blé et de la fétuque ; S(B) : parcelle précédemment en blé seul ; $S(B+F)$ : parcelle précédemment en blé + fétuque; $S(F)$ : parcelle en fétuque seule.

culture n'ayant pas cette possibilité, comme le maïs.

Les traitements expérimentaux ont les mêmes effets sur les productions de biomasse (tiges + feuilles) des blés susceptibles d'alimenter le "pool" de matières organiques des sols que sur les rendements en grains : les mécanismes de compensation ont fait disparaitre les différences initiales. L'absence de corrélation entre les biomasses totales produites par les fétuques et les rendements en grains des blés est liée, d'une part, à la faible pression de compétition exercée par les fétuques pendant le cycle du blé, d'autre part, au faible rapport (production pendant le cycle du blé)/(production après la récolte du blé).

Le choix de la plante de couverture revêt une grande importance. En semis simultané, l'effet bénéfique de l'association sur la croissance de la fétuque au début du cycle du blé semé dense contribue à expliquer la pratique du semis de fétuque sous couvert de blé pour la production de semence de cette espèce (Chastain et Grabe, 1988). Dans nos essais, l'effet de la fétuque sur la réduction de rendement en grains a été très inférieur à celui obtenu par d'autres auteurs avec d'autres graminées associées au blé : ces baisses dépassent fréquemment $20 \%$ et peuvent aller à plus de $90 \%$ (Blackshaw, 2005 ; Lemerle et al., 2004 ; O'Donovan et al., 2005 ; Vandeleur et Gill, 2004 ; Carof et al., 2007a). Le risque d'accroître le développement de maladies sur la culture commerciale est aussi un critère très important de choix, qui conduit à ne pas retenir la fétuque rouge, malgré son intérêt par ailleurs.

La date d'implantation de la plante de couverture est également critique. Le semis simultané permet de réduire significativement la baisse de rendement en grains du blé. Carof et al. (2007a) obtiennent des baisses de rendement pour Isengrain de - 6 à - $78 \%$ pour des couverts (2 graminées, dont Festuca rubra et 4 légumineuses dont Medicago sativa) implantés 6 mois avant le premier semis du blé (moyenne - 38\% pour les graminées, $41 \%$ pour les légumineuses). Pour une implantation dans des luzernes âgées de 1 et 3 mois, Shili-Touzi (2009) observe des baisses allant respectivement de 30 à - $55 \%$ et de - 48 à - $85 \%$ et cela malgré des traitements herbicides au semis du blé pour limiter les effets négatifs des luzernes. Par simulation à partir des données ici présentées, Shili-Touzi et al. (2010) montrent que retarder le semis de la fétuque après celui du blé réduit significativement le risque de baisse de rendement en grains du blé. Mais l'implantation d'une espèce à petites graines comme la fétuque, déjà problématique lors de semis simultané, peut devenir très difficile dans un peuplement de blé déjà établi (observations non publiées).

Un des avantages manifestes du semis simultané d'un blé et d'une plante de couverture est l'accroissement de l'interception du $\mathrm{PAR}_{0}$ dans la période couvrant le cycle du blé et l'interculture qui suit. L'interception par le blé est limitée en raison de sa surface foliaire réduite, d'une part avant le stade "épi à 1 cm ", d'autre part, dans la phase de jaunissement des feuilles (Monteith, 1993). La présence de la plante de couverture permet d'en intercepter une partie dans cette dernière phase (Shili-Touzi et al., 2010). Mais c'est surtout après la récolte de la culture commerciale que la plante de couverture, en exploitant le $\mathrm{PAR}_{0}$ disponible alors que le sol reste nu dans d'autres types de systèmes de culture, permet de produire de la matière organique utilisable à plusieurs fins (Blackshaw et al., 2001 ; Citeau et al., 2008 ; Pelosi et al., 2009; Shili-Touzi et al., 2010). Dans notre cas, la quantité de biomasse produite par la fétuque rouge est relativement plus faible que celle obtenue par d'autres auteurs: 
Blackshaw et al. (2001) citent par exemple une production de 3,1 à 5,4 t/ha de mélilot (Melilotus officinalis (L.) Lam.) semé sous couvert de plusieurs cultures (pois, lin, moutarde) mais sur une période de culture plus longue et avec comme conséquence des baisses de rendement en grains plus fortes des cultures principales (10 à $50 \%$ selon les cultures). Cette production est liée aux arrières effets de l'ombrage subi par les fétuques dans leur phase de croissance en association avec les blés : la structure du couvert est durablement modifiée, comme le montrent les valeurs du coefficient $\mathrm{K}$ d'extinction du rayonnement. Par ailleurs, si les efficiences de transformation du PAR intercepté en biomasse (RUE) sont comparables entre fétuque seule et fétuques précédemment associées, elles sont plus faibles que celle de la fétuque seule dans la période de croissance printanière du fait de l'absence d'élongation des tiges (Bélanger et al., 1992). Elle est également liée au peu d'azote disponible après la récolte du blé, la plante de couverture jouant pleinement son rôle de réduction des risques de lixiviation de l'azote minéral du sol (Whitmore et Schröder, 2007).

\section{Conclusion}

La conception de systèmes de culture plus durables, fondés sur une meilleure valorisation des services écosystémiques, passe par une meilleure valorisation de l'énergie disponible que constitue le rayonnement photosynthétiquement actif et par une meilleure maîtrise du devenir des reliquats azotés après les cultures commerciales.

En climat tempéré, notre essai montre qu'une piste possible est, dans le cas d'intercultures longues - cas d'une culture d'hiver suivie d'une culture de printemps - de semer simultanément la culture d'hiver et une plante de couverture - ce qui implique de détruire la plante de couverture en fin d'interculture. Pour que l'effet de la plante de couverture sur le rendement de la culture commerciale reste limité, il faut un certain nombre de conditions : que l'installation du peuplement de la plante de couverture et son entrée en croissance rapide au printemps soient plus tardifs que celle de la culture commerciale, que sa hauteur soit toujours inférieure et son enracinement significati- vement moins profond; il faut d'autre part que la culture commerciale possède des mécanismes pour compenser la compétition en début de cycle.

La contrepartie de la baisse de rendement observée est une meilleure valorisation du $\mathrm{PAR}_{0}$ à l'échelle du système de culture. Certes, l'association réduit l'efficience d'interception de ce rayonnement. Cependant, l'accroissement de biomasse produite est significatif et ses effets bénéfiques sur l'évolution du taux de matière organique, l'activité de la mésofaune et de celle des micro-organismes du sol ont été montrés par ailleurs. C'est également une réduction du risque de lixiviation de l'azote minéral du sol.

Associer une plante de couverture à une culture principale apparaît donc comme une technique prometteuse afin de progresser vers des systèmes de culture plus durables. Il reste néanmoins à identifier, en particulier pour les systèmes d'agriculture biologique, des plantes de couverture présentant les avantages de la fétuque rouge sans en avoir les inconvénients : le fait qu'une fois implantée elle devienne difficile à détruire, qu'elle soit alors beaucoup plus compétitive vis-à-vis du blé et qu'elle favorise le développement de certaines maladies comme le piétin échaudage.

\section{Remerciements}

Tous nos remerciements à Michel Bourgoin pour son aide dans le choix des variétés de fétuques à associer au blé, à Gilles Grandeau, Béatrice Le Fouillen and Christine Souin pour leur participation très active à la conduite des essais et à toute l'équipe du domaine expérimental de Grignon, dirigée par Jacques Troizier.

Tous nos remerciements également à Marie-Hélène Jeuffroy et Jean RogerEstrade pour leurs précieux commentaires sur le texte.

\section{Références}

Acciaresi HA, Chidichimo HO, Sarandon SJ. Traits related to competitive ability of wheat (Triticum aestivum) varieties against Italian ryegrass (Lolium multiflorum). Biol Agric Hort 2001 ; $19: 275-86$
Angonin C, Caussanel JP, Meynard JM. Competition between winter wheat and Veronica hederifolia: influence of weed density and the amount and timing of nitrogen application. Weed Res 1996 ; $36: 175-87$.

Bélanger G, Gastal F, Lemaire G. Growth analysis of a tall fescue sward fertilized with different rates of nitrogen. Crop Sci $1992 ; 32$ : 1371-6.

Blackshaw RE, Moyer JR, Doram RC, Boswall AL, Smith EG. Suitabilty of undersown sweetclover as a fallow replacement in semiarid cropping systems. Agron J 2001 ; 93 : 863-8.

Blackshaw RE. Nitrogen fertilizer, manure and compost effects on weed growth and competition with spring wheat. Agron J 2005; 97 : 1612-21.

Blaser BC, Gibson LR, Jannink JL. Optimizing seeding rates for winter cereals grains and frost-seeded red clover intercrops. Agron $J$ $2006 ; 98: 1041-9$

Carof M, de Tourdonnet S, Saulas P, Le Floch D, Roger-Estrade J. Undersowing wheat with different living mulches in a no-till system (I): yield analysis. Agron Sustain Dev 2007a; 27 : 347-56.

Carof M, de Tourdonnet S, Saulas P, Le Floch D, Roger-Estrade J. Undersowing wheat with different living mulches in a no-till system (II): competition for light and nitrogen. Agron Sustain Dev 2007b ; 27 : 357-65.

Chastain TG, Grabe DF. Establishment of red fescue seed crops with cereal companion crops. II. Seed production and economic implications. Crop Sci 1988 ; 28 : 313-6.

Citeau L, Bispo A, Brady M, King D, Coord. Gestion durable des sols. Versailles: éditions Quae, 2008.

Derksen DA, Anderson RL, Blackshaw RE, Maxwell $B$. Weed dynamics and management strategies for cropping systems in the Northern Great Plains. Agron J 2002 ; 94 : 174-85.

Fischer RA, Stockman YM. Kernel number per spike in wheat (Triticum aestivum L.): responses to preanthesis shading. Aust JPlant Physiol $1980 ; 7: 169-80$.

Fischer RA. Number of kernels in wheat crops and the influence of solar radiation and temperature. J Agr Sci 1985 ; 105 : 447-61.

Gate P. Écophysiologie du blé. Paris : Lavoisier 1995.

Holland JM. The environmental consequences of adopting conservation tillage in Europe: reviewing the evidence. Agr Ecosyst Environ 2004 $103: 1-25$.

Känkänen $\mathrm{H}$, Eriksson C. Effects of undersown crops on soil mineral $\mathrm{N}$ and grain yield of spring barley. Eur J Agron 2007 ; 27 : 25-34.

Kropff MJ, Van Laar HH. Modelling crop-weed interactions. Wallingford (Great Britain): CABI, 1993.

Lemerle D, Gill GS, Murphy CE, et al. Genetic improvement and agronomy for enhanced wheat competitiveness with weeds. Aust J Agr Res $2001 ; 52$ : 527-48.

Lemerle D, Cousens RD, Gill GS, et al. Reliability of higher seeding rates of wheat for increased competitiveness with weeds in low rainfall environments. J Agric Sci 2004 ; 142 : 395-409. 
Malézieux E, Crozat Y, Dupraz C, et al. Mixing plant species in cropping systems: concepts, tools, and models. A review. Agron Sustain Dev $2009 ; 29: 43-62$.

Masle-Meynard J. Élaboration du nombre d'épis d'un peuplement de blé d'hiver en situation de compétition pour I'azote. II. Modélisation du nombre d'épis. Agronomie 1982 ; 2 : 17-23.

Mason HE, Spaner D. Competitive ability of wheat in conventional and organic management systems : a review. Can J Plant Sci 2006 ; 86 : 333-43.

Meynard JM, David G. Diagnostic de I'élaboration du rendement des cultures. Cah Agric $1992 ; 1$ : 9-19.

Monteith JL. The exchange of water and carbon by crops in a Mediterranean climate. Irrig Sci $1993 ; 14: 85-91$.

O'Donovan JT, Blacshaw RE, Harker KN, Clayton GW, McKenzie R. Variable crop plant establishment contributes to differences in competitiveness with wild oat among cereal varieties. Can J Plant Sci 2005 ; 85 : 771-6.

Pelosi C, Bertrand M, Roger-Estrade J. Earthworm community in conventional, organic and direct seeding with living mulch cropping systems Agron Sustain Dev $2009 ; 29$ : 287-95.
Picard D, Ghiloufi M, Saulas P, de Tourdonnet S Does undersowing winter wheat with a cover crop increase competition for resources and is it compatible with high yield? Field Crops Res 2010; 115 : 9-18. Field Crops Res 2010; 116 : 206 (Erratum).

SAS Institute Inc. SAS OnlineDoc. Version 8. Cary (North Carolina, USA) : SAS Institute, 1999 [Online].

Sebillotte M. An analysis of yield elaboration in wheat. In: Wheat. Technical monograph. Bâle (Suisse) : Documenta CIBA-GEIGY, 1980.

Shili-Touzi I. Analyse du fonctionnement d'une association de blé d'hiver (Triticum aestivum L.) et d'une plante de couverture sur une échelle annuelle par modélisation et expérimentation. Thèse de doctorat, AgroParisTech, Paris, 2009.

Shili-Touzi I, Tourdonnet S, de, Launay M, Dore T. Does intercropping winter wheat (Triticum aestivum) with red fescue (Festuca rubra) as a cover crop improve agronomic and environmental performance? A modeling approach. Field Crops Res $2010 ; 116$ : 218-29.
Thorsted MD, Olesen JE, Weiner J. Mechanical control of clover improves nitrogen supply and growth of wheat in wheat/white clover intercropping. Eur J Agron 2006 ; 24 : 149-55.

Vandeleur RK, Gill GS. The impact of plant breeding on the grain yield and competitive ability of wheat in Australia. Aust J Agr Res 2004; 55: 855-61.

Vandermeer $\mathrm{JH}$. The ecology of intercropping. New York: Cambridge University Press, 1989.

Varlet-Grancher C, Gosse G, Chartier M, Sinoquet $\mathrm{H}$, Bonhomme $\mathrm{R}$, Allirand $\mathrm{J}-\mathrm{M}$. Mise au point: rayonnement solaire absorbé ou intercepté par un couvert végétal. Agronomie 1989 ; $9 \cdot 419-39$

Whitmore AP, Schröder JJ. Intercropping reduces nitrate leaching from under field crops without loss of yield: a modelling study. Eur J Agron 2007 ; 27 : 81-8.

Zadoks JC, Chang TT, Knozak CF. A decimal code for the growth stages of cereals. Weed Res $1974 ; 14: 415-21$. 